\title{
Restricted diet rescues rat enteric motor neurones from age related cell death
}

\author{
T Cowen, R J R Johnson, V Soubeyre, R M Santer
}

\begin{abstract}
Background-Alone among autonomic neurones, enteric neurones are known to be vulnerable to age related cell death; over $50 \%$ may be lost in aging rodents. A previous study demonstrated unexpectedly that neurones of the myenteric plexus from rats fed a restricted diet appeared not to suffer from extensive cell death in contrast with previous studies of ad libitum fed animals.
\end{abstract}

Aims-To compare myenteric neurone numbers in the ileum of young and aging male Sprague-Dawley rats fed either ad libitum or a restricted diet.

Methods-Neurones were counted in whole mount preparations of rat ileum stained immunohistochemically for the pan-neuronal marker PGP9.5, for choline acetyltransferase, or for nitric oxide synthase, or with NADH or NADPH histochemistry.

Results-Neurone numbers in the rat myenteric plexus were substantially affected by the dietary regimen: ad libitum feeding (50-60 g per day of standard rat chow) resulted in the death of about $50 \%$ of myenteric neurones in 24 month Sprague-Dawley rats, while numbers were unchanged when the daily dietary intake was halved between the ages of six and 24 months. Animals fed a double restricted diet (15 g per day) showed no cell loss at 30 months, as well as the predicted increase in longevity. Neurone loss was largely complete by 16 months in ad libitum fed animals. Numbers of cholinergic (possibly motor) neurones, as demonstrated by choline acetyltransferase immunohistochemistry, were substantially reduced in ad libitum fed aging rats but not in animals fed a restricted diet. Loss of cholinergic neurones after ad libitum feeding was confirmed by reduced numbers of neurones of a size range matching that of cholinergic neurones.

Conclusions-Ad libitum feeding of adult rats has adverse effects on the survival of myenteric neurones, neurone loss commencing before 16 months of age. Cholinergic neurones appear to be particularly vulnerable to the effects of diet. Restricting dietary intake from six months of age prevents neurone loss almost entirely up to 30 months of age in these rats.

(Gut 2000;47:653-660)

Keywords: restricted diet; enteric neurones; aging; neuronal cell death
Aging involves impairment of gastrointestinal function, including reductions in gastric emptying time and the frequency and amplitude of the peristaltic wave in elderly patients. ${ }^{1}$ Transit through the colon slows ${ }^{2}$ and there are changes in digestion and absorption of foodstuffs (for review see Hosoda and colleagues ${ }^{3}$ ). Aging is also associated with a significant decline in gastric blood flow and certain mucosal protective mechanisms may be compromised. ${ }^{4}$

The structural correlates of these functional impairments remain poorly understood. The myenteric plexus consists of many millions of neurones (estimates made in guinea pigs vary from $2.75^{5}$ to $6.75^{6}$ million neurones in the small intestine alone) distributed throughout the gastrointestinal tract in a two dimensional interconnected plexus of ganglia within the muscularis externa. Quantitative studies of total neuronal numbers within the myenteric plexus have demonstrated extensive losses of $40-60 \%$ in senescent rats $^{7}$ and guinea pigs, ${ }^{5}$ and $20-62 \%$ in humans, affecting the whole of the gastrointestinal tract. For example, in elderly humans significant cell loss has been noted in the small intestine, ${ }^{8}$ oesophagus, ${ }^{9}$ and colon. ${ }^{10}$ Peptidergic nerve fibres ${ }^{11}$ and the extrinsic noradrenergic nerve supply to the gut from the coeliac superior mesenteric ganglion ${ }^{12}$ are also reduced in the gastrointestinal tract of aged rats.

Diet has a pronounced and well established effect on longevity in rodents. The lifespan of rats is significantly increased by a $40 \%$ reduction of food intake compared with that given to freely fed animals. ${ }^{13}$ Animals kept on such a diet are less prone to disease and are generally healthier. ${ }^{14}$ We have previously shown ${ }^{15}$ that aging Sprague-Dawley rats fed on a restricted diet of approximately half their maximal daily intake failed to exhibit the $50-60 \%$ loss of neurones previously described in aging rats, ${ }^{16}$ albeit of a different strain (Wistar).

The functional impairments of the aging gut previously described suggest that particular subpopulations of myenteric neurones may be more vulnerable than others. Loss of motility may involve intrinsic excitatory cholinergic neurones. Organ bath experiments have revealed significant reductions in the cholinergic component of neuromuscular transmission in the aging rat gut. ${ }^{17}$ There is also a reduction with age in acetylcholine release and in smooth muscle responsiveness in the rat colon, ${ }^{17}$ perhaps resulting in a reduction of colonic

Abbreviations used in this paper: ChAT, choline acetyltransferase; NOS, nitric oxide synthase; NO, nitric oxide; PBS, phosphate buffered saline. 
function. ${ }^{18}$ Cholinergic neurones (expressing choline acetyltransferase (ChAT) activity) constitute a majority in the guinea pig $^{19}$ and human myenteric plexus of the large and small intestine,${ }^{20}$ loss of which may explain the high incidence of constipation in elderly patients. ${ }^{21}$

Nitric oxide (NO) is generated by nitric oxide synthase (NOS) in nitrergic inhibitory neurones of the gut (for review see Brookes ${ }^{22}$ ) where it can be demonstrated using the NADPH-diaphorase method ${ }^{23}$ as well as by immunohistochemistry. ${ }^{24}$ In Wistar rats, nitrergic neurones, demonstrated by $\mathrm{NADPH}$ staining, constituted approximately $27 \%$ of myenteric neurone numbers. ${ }^{25}$ NOS neurones are selectively spared in the myenteric plexus of aging Wistar rats ${ }^{26}$ and increase as a proportion of the total in the proximal colon of aging Sprague-Dawley rats. ${ }^{27}$ In Alzheimer's disease, the relative proportion of nitrergic neurones in the striatum also increases, ${ }^{28}$ suggesting that these neurones may be generally less vulnerable to age related disease.

We have conducted a systematic comparison of myenteric neurone numbers from aging Sprague-Dawley rats fed ad libitum or a restricted diet, using whole mount preparations stained either with the pan-neuronal immunohistochemical marker PGP9.5, ${ }^{6}{ }^{29}$ or with the more widely used NADH-diaphorase histochemical stain. ${ }^{57}$ PGP9.5 has been shown previously ${ }^{29}$ to stain at least $80 \%$ of myenteric neurones in the rat. The hypothesis that diet is a crucial determinant of age related cell death in enteric neurones was examined and the time course of these changes was investigated. In addition, we double restricted the diet of adult rats, deferring senescence (the age at which $50 \%$ of animals die) to 30 months and studied the numbers of myenteric neurones in these animals. Using selective staining, the numbers of cholinergic and nitrergic neurones in the myenteric plexus of rats subjected to different dietary regimes were compared in an attempt to discover whether either of these populations of neurones are vulnerable to cell death or are selectively spared.

\section{Methods}

ANIMALS AND DIETARY MAINTENANCE

Male Sprague-Dawley rats of 4-6, 16, 20, and 24 months were housed in groups of three and fed ad libitum (AL) daily with standard rat chow with boosted vitamins and essential fatty acids (BEEKAY Rat and Mouse Standard Diet (expanded), B\&K Universal Ltd, Hull, UK) which consisted of $20 \%$ crude protein, $4 \%$ crude oil, $4 \%$ crude fibre, and $72 \%$ dry matter. The caloric content was $16.16 \mathrm{~mJ} / \mathrm{kg}$. AL rats consumed an average of $47 \mathrm{~g}$ per day each. Further rats were maintained for 24 months on a restricted diet (RD) of $25 \mathrm{~g}$ per day from the age of six months ${ }^{15}$ while a group of animals was kept for 30 months on a "double restricted" diet (DRD) of $15 \mathrm{~g}$ per rat per day. Animals were weighed and monitored individually at regular intervals. All husbandry conditions were approved and licensed by the Home Office (PPL 70/4556) and subject to regular veterinary inspection.
TISSUE PREPARATION

Methods have been described in detail previously. ${ }^{15}$ Briefly, animals were terminally anaesthetised with Euthesate, and the whole of the small intestine was resected close to the ileocaecal junction, removed, and flushed with Krebs solution to remove gut contents. The small intestine was sealed at both ends with cotton thread and dilated with Krebs solution to a similar pressure in all animals, judged by the point at which the intestine started to curl. Length and circumference were then measured. A $10 \mathrm{~cm}$ length was tied off and fixed in $4 \%$ paraformaldehyde in phosphate buffered saline (PBS) for two hours at $4^{\circ} \mathrm{C}$, washed in HEPES buffer, and placed in $20 \%$ sucrose PBS overnight at $4^{\circ} \mathrm{C}$. Two or more $1 \mathrm{~cm}$ wide strips per animal, including circular and longitudinal muscle and the myenteric plexus, were peeled off and rinsed in buffer.

\section{IMMUNOHISTOCHEMISTRY}

Whole mount preparations were stained immunohistochemically for PGP (to demonstrate total neurone numbers) ${ }^{15}$ and for ChAT (to demonstrate cholinergic enteric motor neurones). To enhance visualisation of ChAT staining, tissues were preincubated at $37^{\circ} \mathrm{C}$ for 24 hours in tissue culture medium (DMEM F12) containing $0.25 \mathrm{ml}$ of a $10 \mathrm{mg} / \mathrm{ml}$ gentamycin solution, $1 \mathrm{ml}$ penicillin/ streptomycin solution (5000 U), $0.5 \mathrm{ml}$ of a $0.25 \mathrm{mg} / \mathrm{ml}$ amphotericin B solution, $1 \mathrm{ml}$ of pig serum, and $7 \mathrm{mg}$ of the axonal transport inhibitor colchicine (all Sigma Aldrich, UK) (method modified from Steele and colleagues $^{30}$ ). After washing, specimens for PGP and ChAT staining were treated with $0.3 \%$ Triton X-100 for 20 minutes and 5\% swine serum for 1.5 hours followed by overnight incubation in ChAT antibody raised in rabbits (a generous gift from $\mathrm{Dr} M$ Schemann) or PGP antibody, both diluted 1:400 in HEPES buffer containing $0.1 \%$ Triton $\mathrm{X}-100,5 \%$ swine serum, $0.05 \%$ sodium azide, and $0.05 \%$ DL-lysine. Specimens were washed three times in PBS, incubated for two hours in a 1:40 dilution of secondary antibody labelled with FITC (Dako, Denmark), and counterstained with a $0.05 \%$ solution of pontamine sky blue for five minutes to reduce background autofluorescence. ${ }^{31}$ Specimens were mounted in antifade mountant (Citifluor, $\mathrm{UK})$.

\section{NADH histochemistry}

Gut segments were dilated with Krebs solution as above, pretreated in $0.3 \%$ Triton X-100 for eight minutes and incubated for 60-90 minutes in $0.1 \%$ Triton $\mathrm{X}-100,30 \mathrm{mg}$ nitroblue tetrazolium, $30 \mathrm{mg} \mathrm{NADH}$ (all Sigma, UK), $45 \mathrm{ml}$ distilled water, and $15 \mathrm{ml}$ phosphate buffer $^{32}$ at room temperature. Progress of staining was monitored to maximise contrast between $\mathrm{NADH}$ positive neurones and background. The specimens were rinsed in Krebs and fixed in $4 \%$ paraformaldehyde for 24 hours at $4^{\circ} \mathrm{C}$. Muscle strip preparations were made as described and mounted in PBS glycerol (Aquamount, BDH, UK). 
Table 1 Correction factors derived from measurements $(\mathrm{cm})$ of length and circumference (measured at 3-5 points along its length) of the ileum, allowing comparisons of nerve density in the small intestine from the different groups of animals (see methods). Data for 24 month $R D$ rats from Fohnson and colleagues ${ }^{15}$

\begin{tabular}{llllll}
\hline $\begin{array}{l}\text { Age group } \\
\text { (months) }\end{array}$ & $n$ & Length (cm) & Circ. (cm) & Area $\left(\mathrm{cm}^{2}\right)$ & Correction factor \\
\hline $4-6 \mathrm{~m}$ & 16 & $110(3)$ & $1.3(0.03)$ & $136(5)$ & Standard \\
AL $16 \mathrm{~m}$ & 4 & $118(10)$ & $1.5(0.04)$ & $175(15)$ & 1.29 \\
AL $24 \mathrm{~m}$ & 9 & $111(4)$ & $1.4(0.04)$ & $159(7)$ & 1.17 \\
RD $24 \mathrm{~m}$ & 10 & $145(4)$ & $1.3(0.03)$ & $194(5)$ & 1.43 \\
DRD $30 \mathrm{~m}$ & 4 & $110(3)$ & $1.5(0.01)$ & $159(6)$ & 1.17 \\
\hline
\end{tabular}

$\mathrm{AL}$, ad libitum; $\mathrm{RD}$, restricted diet; $\mathrm{DRD}$, double restricted diet.

\section{NADPH histochemistry}

Gut segments were fixed for 30 minutes in 4\% paraformaldehyde at $4^{\circ} \mathrm{C}$, washed in $\mathrm{Krebs}$ solution and incubated for two hours at $37^{\circ} \mathrm{C}$ in medium consisting of $30 \mathrm{mg} \mathrm{NADPH}$ (Sigma, UK), $30 \mathrm{mg}$ nitroblue tetrazolium, $0.1 \%$ Triton X-100 in $45 \mathrm{ml}$ distilled water, and $15 \mathrm{ml}$ phosphate buffer. Progress of the reaction was again monitored after which specimens were removed and muscle strips were prepared and mounted in Aquamount as before. Orientation of specimens was maintained by clipping one corner of the tissue.

QUANTIFICATION OF NEURONE NUMBERS

After histochemical staining, positively stained cell bodies were counted on a twin bank counter under transmitted light on a Nikon Optiphot microscope equipped with a $\times 10$ lens, using an eyepiece graticule which framed an area of $1.03 \mathrm{~mm}^{2}$ on the specimen. Following immunohistochemistry, neurones were counted using an Olympus $\mathrm{AH}-2$ fluorescence microscope equipped with $\mathrm{a} \times 20$ objective and an eyepiece graticule which defined an area of $0.059 \mathrm{~mm}^{2}$. Three series of frames were counted on each specimen, parallel to the longitudinal axis of the gut, two of which were on either side of the mesenteric aspect and one of which was from the anti-mesenteric aspect. Those neurones lying within the field area were counted, as were those intersecting the bottom and right hand edges of the graticule perimeter. About 50 frames were counted from each specimen, and the counts pooled for subsequent statistical analysis.

CORRECTION FOR GROWTH OF THE INTESTINE Neurone density can be assumed to be affected by alterations in size of the intestine, where growth will "dilute" neurone numbers over the increased surface area. The rat intestine grows with age ${ }^{1516}$ and the extent of growth may be affected by diet. Measurements of length and circumference of the dilated ileum were therefore made and used to calculate a correction factor by which counts of neurones in the different age groups were multiplied (table 1). Corrected cell counts were expressed as mean (SEM) positively stained neurones per $\mathrm{cm}^{2}$. Differences between data sets were compared by ANOVA followed by Tukey's HSD test or Student's $t$ test where appropriate.

REGIONAL DISTRIBUTION AND SIZE OF MYENTERIC NEURONES

The density of myenteric neurones over mesenteric (adjacent to the attachment of the mesentery) and anti-mesenteric surfaces of the distal ileum were examined in four month and 24 month $\mathrm{AL}$ and $\mathrm{RD}$ groups stained with PGP. In an attempt to discover if neurone loss was associated with a particular size population of neurones, maximum and minimum diameters of a representative sample of 150 neurones taken from a number of animals in each treatment group were measured on PGP stained whole mount preparations using a calibrated eyepiece graticule in a Nikon light microscope and a $\times 40$ objective. Similar measurements were made on cholinergic neurones from the 24 month $\mathrm{RD}$ group. Average diameter per neurone was calculated and frequency distributions plotted; average diameters and standard error were also calculated for each treatment group.

\section{Results}

PGP IMMUNOHISTOCHEMISTRY

In young rats, the myenteric plexus stained with PGP9.5 had the typical appearance seen in previous studies, including primary, secondary, and dense tertiary components (fig 1). Ganglia were packed with clearly visible neurones. In contrast, the ganglia from AL 16 and 24 month rats showed fewer neurones and obvious gaps in the myenteric ganglia (fig 1), suggesting neurone loss. The appearance of ganglia from the AL groups was variable with some ganglia showing normal neurone staining and others showing evidence of substantial neurone loss. The visual impression indicated that neurodegeneration was already maximal by 16 months (fig 2). Some preparations were stained with toluidine blue to test if "gaps" in ganglia may have been due to loss of neuronal PGP staining rather than neurone loss. No staining was observed within these profiles (data not shown) confirming that PGP staining was a reliable indicator of neurone loss. PGP staining of RD 24 month and DRD 30 month rat ileum showed no obvious loss of neurones from myenteric ganglia, with the ganglia resembling those of preparations from young rats. Counts of neurones gave an areal density of 19900 (1100) cells $/ \mathrm{cm}^{2}$ in young rats (table 2 , fig 2). In the AL groups, neurone densities were reduced by $66 \%$ at 16 months, by $57 \%$ at 20 months, and by $52 \%$ at 24 months. ANOVA and subsequent testing showed that the differences between these and the young values were highly significant $(\mathrm{p}<0.001)$ (table 2$)$. There were no significant differences between the AL groups indicating that the majority of neurone loss had already occurred by 16 months. Neurone counts from preparations of RD 24 month and DRD 30 month ileum revealed numbers that were closely similar to those seen in young rats and significantly different from AL 24 month preparations $(\mathrm{p}<0.001$ in both cases) (table 2; figs 1,2). Unexpectedly, no obvious differences were observed in the secondary and tertiary plexuses of the different groups, although in some of the preparations from aged rats (RD and $\mathrm{AL}$ ) there were variable areas of diminished density of the tertiary plexus (data not shown). 

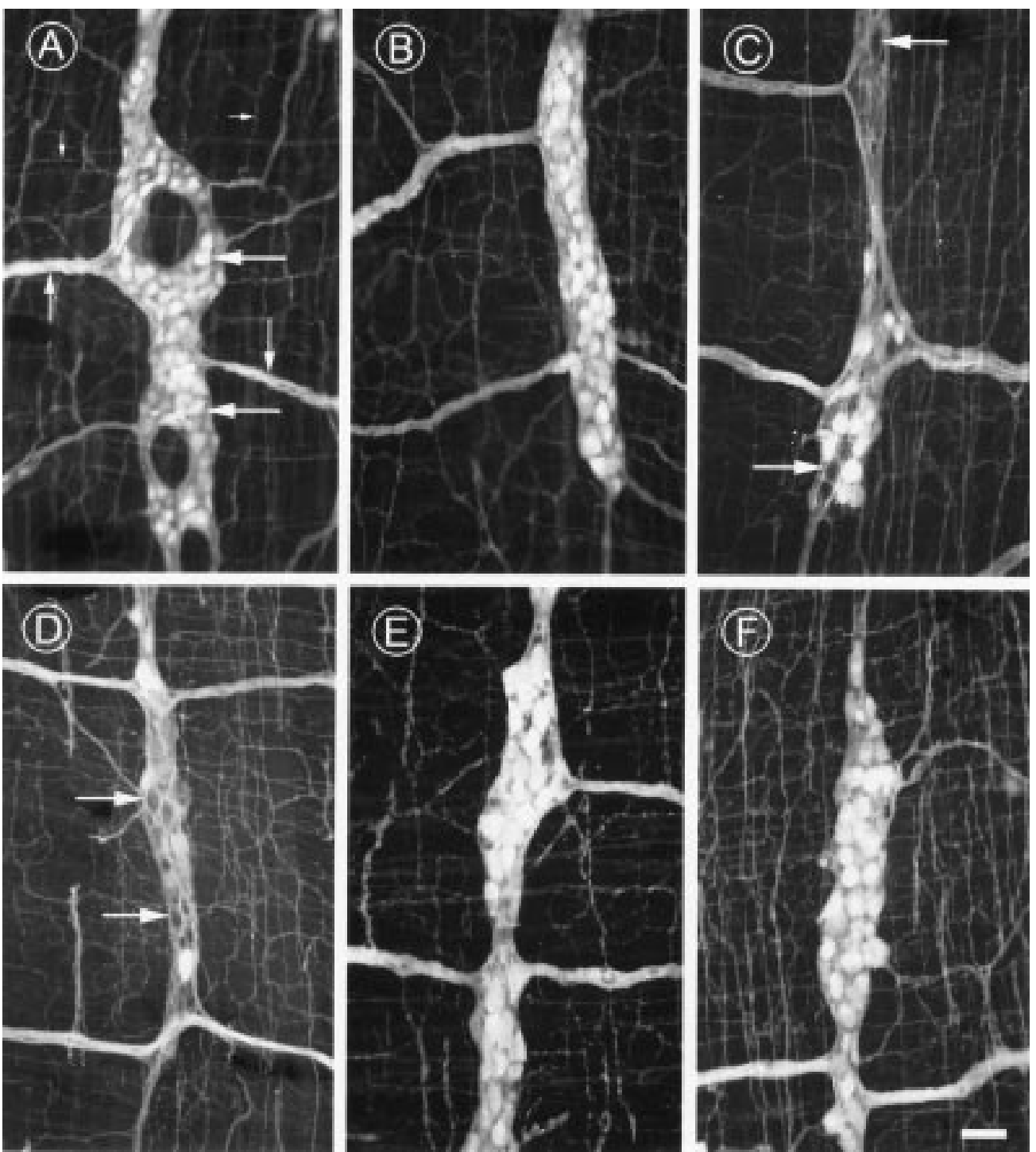

Figure 1 Photomicrographs showing PGP immunoreactive neurones in the myenteric plexus of young (4-6 month (A)), ad libitum ( $A L)$ fed ( $A L 16$ month $(B, C), A L 24$ month $(D)$ ), and restricted diet (RD 24 month $(E)$ and double RD 30 month (F)) rats. Note the ganglion full of brightly stained neurones in (A) (large arrows), and also in (B), (E), and (F). The secondary (medium arrows) and tertiary (small arrows) plexuses are also seen in all preparations. Nerve loss is clearly seen as spaces within the majority of ganglia in AL 16 month and AL 24 month animals (C, D) (arrows) but not in all AL animals (B). Scale bar $50 \mu \mathrm{m}$.

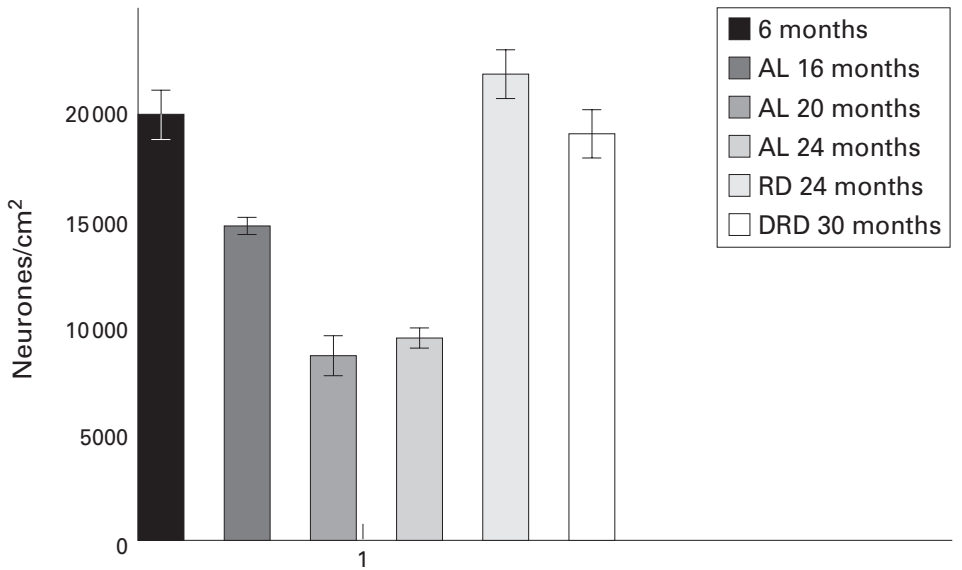

Figure 2 Histogram showing the number of PGP immunoreactive neurones in the myenteric plexus of young (4-6 month) rats, ad libitum fed $(A L)$ rats at 16, 20, and 24 months, rats fed a restricted diet (RD) at 24 months, and rats fed a double restricted diet (DRD) at 30 months. Note the comparable loss of neurones in AL 16, AL 20, and AL 24 month groups compared with young, RD 24 month and DRD 30 month groups. These losses were highly significant (see table 2), reaching $>50 \%$ in the AL groups. Also, note the lack of cell loss in senile (DRD 30 months) animals fed a double restricted diet.
NADH-DIAPHORASE HISTOCHEMISTRY

The numerous positively stained neurones were apparent and easily counted due to the intensity of formazan product in the neuronal perikarya (fig 3). The nuclei were left unstained in all preparations. Mean areal density of neurones in preparations from young rats was 9700 (600) cells $/ \mathrm{cm}^{2}$ (table 2) - that is, about half the number of neurones stained with PGP9.5..$^{15}$ In 24 month AL rats, the intensity of staining in the cell bodies and background was similar to that observed in young myenteric ganglia but the packing density and total numbers of neurones within the ganglia were much reduced (fig 3). Neurone density was substantially less (43\%) compared with young animals (table 2 ). In contrast with the results of PGP staining, $\mathrm{NADH}$ showed some reduction of neurone numbers in RD 24 month rats (16\%; table 2) compared with young values. In both the 24 month groups the size of neurones appeared to 
Table 2 Corrected cell counts, expressed as neurone number $\times 10^{3}$ per $\mathrm{cm}^{2}$ (data for RD 24 month rats from fohnson and colleagues ${ }^{15}$ )

\begin{tabular}{|c|c|c|c|c|c|c|}
\hline & 4-6 months & $\begin{array}{l}\text { AL } 16 \\
\text { months }\end{array}$ & $\begin{array}{l}\text { AL } 20 \\
\text { months }\end{array}$ & $\begin{array}{l}\text { AL } 24 \\
\text { months }\end{array}$ & $\begin{array}{l}R D 24 \\
\text { months }\end{array}$ & $\begin{array}{l}\text { DRD } 30 \\
\text { months }\end{array}$ \\
\hline PGP & $\begin{array}{l}19.9(1.1) \\
(5)\end{array}$ & $\begin{array}{l}6.8(0.65)^{\mathrm{bd}} \\
(4)\end{array}$ & $\begin{array}{l}8.6(1.6)^{\mathrm{bd}} \\
(3)\end{array}$ & $\begin{array}{l}9.5(0.5)^{\mathrm{bd}} \\
(18)\end{array}$ & $\begin{array}{l}21.9(1.1) \\
(6)\end{array}$ & $\begin{array}{l}19.2(1.1) \\
(9)\end{array}$ \\
\hline $\mathrm{NADH}$ & $\begin{array}{l}9.7(0.6) \\
(20)\end{array}$ & - & $\begin{array}{l}5.0(0.4)^{\mathrm{ad}} \\
(6)\end{array}$ & $\begin{array}{l}5.1(0.4)^{\mathrm{bd}} \\
(12)\end{array}$ & $\begin{array}{l}8.1(0.3)^{c} \\
(33)\end{array}$ & - \\
\hline ChAT & $\begin{array}{l}16.3(0.5) \\
(4)\end{array}$ & - & - & $\begin{array}{l}5.7(0.3)^{\mathrm{bd}} \\
(4)\end{array}$ & $\begin{array}{l}17.4(1.1) \\
(4)\end{array}$ & - \\
\hline $\begin{array}{l}\text { NADPH/ } \\
\text { NOS }\end{array}$ & $\begin{array}{l}2.7(0.1) \\
(17)\end{array}$ & - & & $\begin{array}{l}2.6(0.4) \\
(4)\end{array}$ & $\begin{array}{l}3.1(0.4) \\
(14)\end{array}$ & - \\
\hline
\end{tabular}

$\mathrm{AL}$, ad libitum; RD, restricted diet; DRD, double restricted diet.

${ }^{\mathrm{a}} \mathrm{p}<0.01,{ }^{\mathrm{b}} \mathrm{p}<0.001,{ }^{\mathrm{c}} \mathrm{p}<0.05$ compared with young (4-6 month) rats; ${ }^{\mathrm{d}} \mathrm{p}<0.001$ compared with $\mathrm{RD}$ 24 month rats.

Values in italics indicate number of animals.

be larger compared with those from young animals (fig 3 ).

NOS NEURONES

NO synthesising neurones were stained with NADPH histochemistry, which stained similar groups of neurones to those stained using immunohistochemistry for NOS (fig 4). ${ }^{15}$ Relatively sparse, positively stained neurones located principally at the periphery of ganglia and nerve fibres in secondary and tertiary elements of the plexus were seen. Neurone density was 2700 (100) cells $/ \mathrm{cm}^{2}$ (table 2) - that is, about $15 \%$ of the total of about 20000 (see above). In 24 month AL rats, staining of the larger nerve bundles seemed fainter, and the tertiary plexus was less evident. However, neurone density (2400 (300) cells $\left./ \mathrm{cm}^{2}\right)$ was not significantly reduced.

CHOLINERGIC NEURONES

Following colchicine treatment, staining for ChAT revealed abundant and generally large neurone cell bodies in the ganglia and large fibre bundles in the myenteric plexus of four month old rats. Staining was relatively faint making photography difficult because of the low level of fluorescence. However, neurones could be reliably counted and were checked by second observers. Neurone density was 16300 (500) cells $/ \mathrm{cm}^{2}$ (table 2) - that is, cholinergic neurones comprised a large proportion of the total numbers revealed by PGP staining. In AL 24 month rats, the number of stained neurones was reduced by $64 \%$ (5700 (300) cells $/ \mathrm{cm}^{2}$; $\mathrm{p}<0.001$ ) (table 2) compared with that seen in young rats.

\section{REGIONAL DISTRIBUTION AND SIZE OF MYENTERIC} NEURONES

Neurones were more densely distributed on the mesenteric surface compared with the antimesenteric surface of the gut wall. Neurone loss also appeared greater on the mesenteric surface (data not shown). Studies of neurone size from PGP stained preparations showed that neurones continued to grow after six months of age (fig 5). Mean diameter increased significantly from six months $(12.4(0.59))$ to 16 months $(17.1$ (1.17)) ( $\mathrm{p}<0.001)$. There was a further small increase in mean size in the 24 month AL group (19.4 (1.66)) which was significantly different from the 24 month RD and 16 month AL groups $(\mathrm{p}<0.05)$. The majority of neurones in the 24 month $\mathrm{RD}$ groups were distributed over a size range from 15 to $25 \mu \mathrm{m}$, while in the 24 month AL group, depletion of a subpopulation of neurones with diameters of approximately $15-17 \mu \mathrm{m}$ was shown (fig 5). This size group matched the diameter of cholinergic neurones measured from the 24 month RD group (data not shown) confirming that smaller cholinergic neurones were involved in neurone loss and that the changes observed with ChAT staining were probably due to neurone loss rather than reduced levels of neuronal ChAT.

\section{Discussion}

The effects of diet on the developing nervous system have been widely investigated. Undernutrition in pre- and/or postnatal life is associated with reduced numbers of myenteric

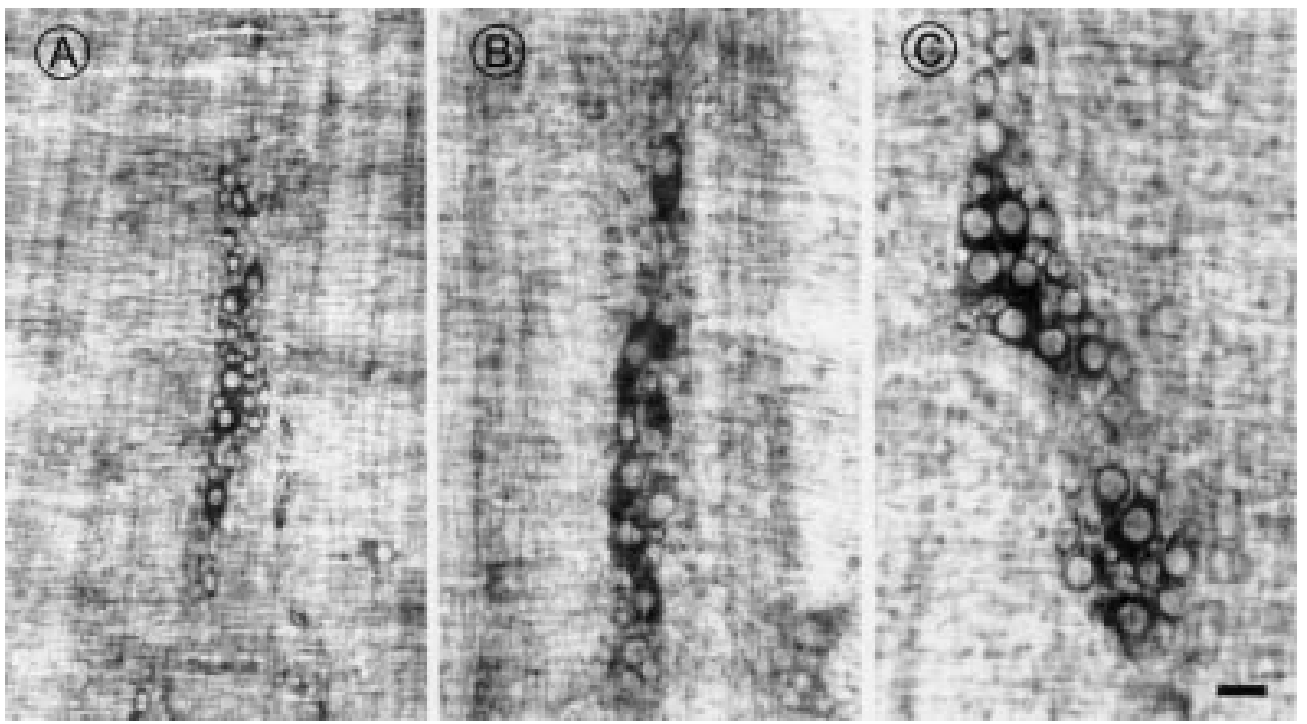

Figure 3 Photomicrographs showing NADH histochemical staining in the myenteric plexus of young 4-6 month (A), old ad libitum fed (AL 24 month) (B), and restricted diet (RD 24 month) (C) rats. Note the reduced density of neurones in ganglia from $A L(B)$ as well as $R D(C)$ rats, indicating that $N A D H$ is not suitable as a pan-neuronal marker (see text and table 1). Also, note the increased size of neurones in (B) and (C). Scale bar $50 \mu \mathrm{m}$. 


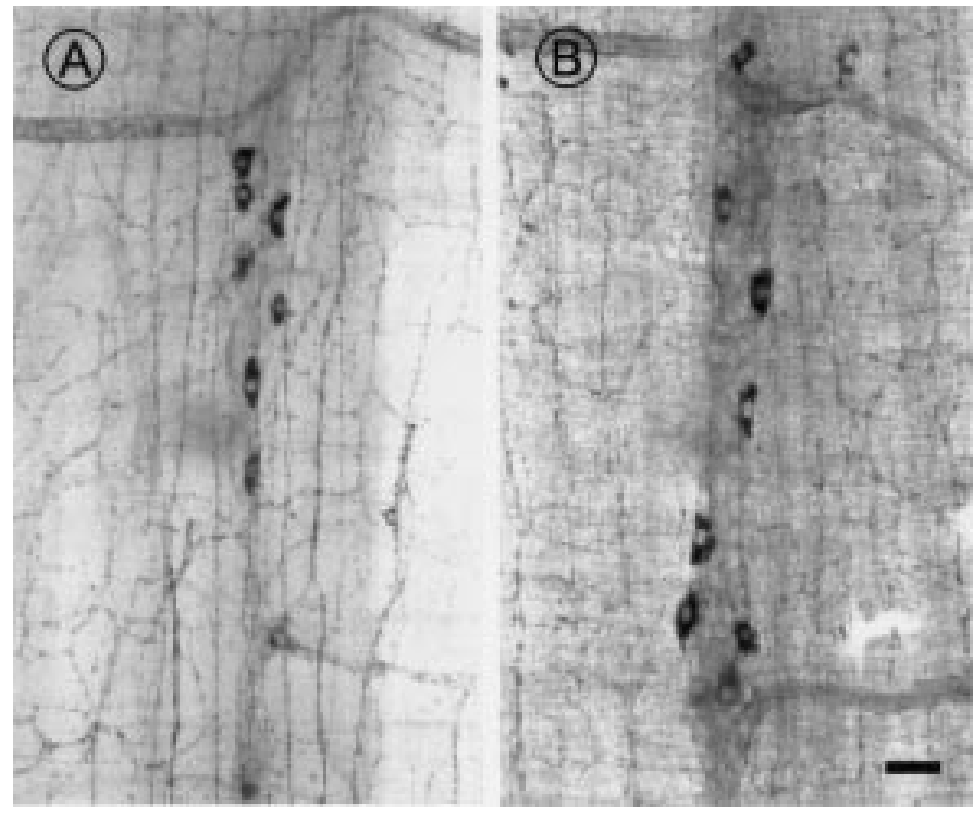

Figure 4 Photomicrographs showing NADPH histochemical staining for nitrergic neurones in ganglia from the myenteric plexus of young $(A)$ and ad libitum fed 24 month (B) rats. Note the comparable density of stained neurones. Scale bar $50 \mu \mathrm{m}$.

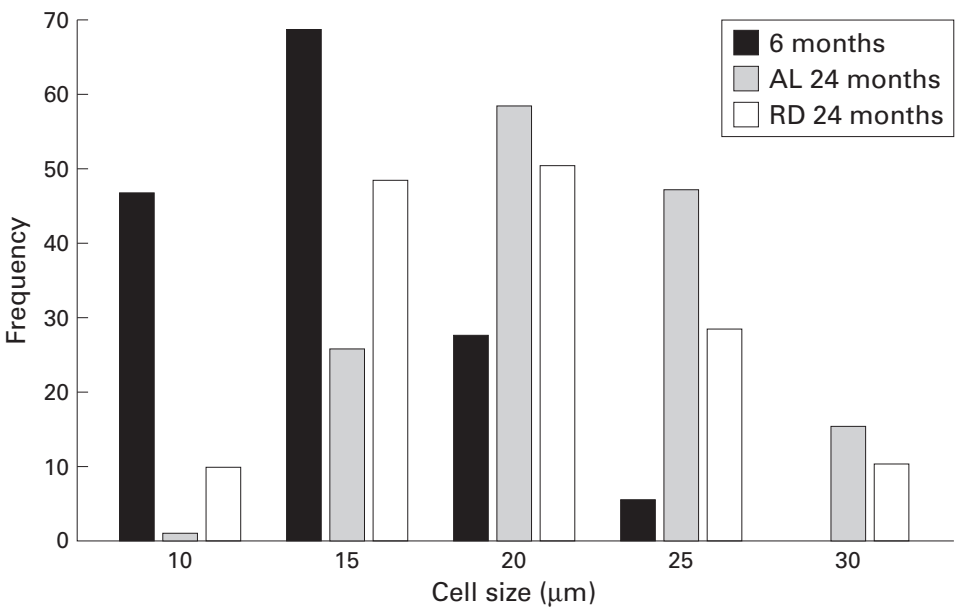

Figure 5 Histogram showing size (average diameter) distributions of neurones in different age groups following ad libitum $(A L)$ and restricted diet (RD) feeding in 24 month old rats. Note the rightward shift of neurone sizes at all ages after six months, indicating continued neurone growth in adult life. The frequency of neurones of 15-17.5 $\mu$ m diameter is reduced in the 24 month AL group compared with the 24 month RD group, matching the average size of cholinergic neurones measured separately in neurones from 24 month RD rats (data not shown). day) increased the age of senescence to 30 months, as previously reported, ${ }^{13}$ and also prevented significant loss of myenteric neurones up to that age.

These data permit reinterpretation of the apparently conflicting data regarding the effects of age on myenteric neurone numbers in rodents, where rats were found to exhibit either major losses ${ }^{7}$ or no loss $^{15}$ of myenteric neurones in old age. In the former study, Wistar rats were fed ad libitum, while in the latter, SpragueDawley rats were fed a restricted diet (see above). Despite the different strains of rat, our results suggest that differences in dietary regimen may be sufficient to explain the contrasting results.

The time course of the effects of diet on rat myenteric neurone loss has been examined. Cell loss was already extensive by 16 months of age, suggesting that ad libitum feeding from six months may already begin to have adverse effects on neurone numbers before 16 months - that is, long before senescence sets in. This result suggests that diet induced cell loss is not necessarily related to old age. It is interesting to note that studies of guinea pigs showing age related loss of myenteric neurones ${ }^{5}$ were also carried out on ad libitum fed animals. Here too, diet may have contributed to the effects of increasing age on numbers of myenteric neurones. However, in ad libitum fed guinea pigs, cell loss occurred after 26 months - that is, it is more likely to be age related than in rats.

Cell loss affected particularly the cholinergic group of myenteric neurones. Neurones expressing ChAT comprise a substantial majority $(82 \%)$ of the total (this study and see Schemann and colleagues $\left.{ }^{19}\right)$. This proportion decreased to $62 \%$ in AL 16 and 24 month rats. Reduced neuronal content of ChAT may contribute to the observed changes in staining. However, the reduced number of ChAT positive cells matched closely the reductions in neurone numbers demonstrated by the panneuronal marker PGP. Our analysis of neurone size distributions suggested that cholinergic neurones are involved in neurone loss. Furthermore, the other population of neurones examined (those staining for NOS/NADPH) did not show age or diet related changes. In the absence of data on other groups of neurones, we tentatively suggest that cholinergic excitatory motor neurones represent the principal subpopulation of myenteric neurones vulnerable to the effects of diet. Loss of cholinergic neurones may underlie loss of motility in the aging gut, including increased incidence of constipation in the elderly (see introduction and McDougal and colleagues ${ }^{18}$ and Merkel and colleagues ${ }^{21}$ ). Neurone loss may also explain observations such as altered cholinergic neuromuscular transmission in the aging rat gut ${ }^{17}$ and reduced acetylcholine release and smooth muscle responsiveness in the rat colon. ${ }^{35}$ Cholinergic neurones are vulnerable in the ventral striatum in Parkinson's disease ${ }^{36}$ and in the nucleus basalis of Meynert in non-pathological aging as well as in Alzheimer's disease, suggesting that some gen- 
eral, but as yet unknown, feature of cholinergic neurones may contribute to their vulnerability in age related pathologies (for reviews see Wurtman $^{37}$ and Balaskas and colleagues ${ }^{38}$ ).

In contrast with changes in cholinergic neurones, there was no significant change in NOS stained neurones. Consequently, there was a small increase in the proportion of NOS positive cells from $17 \%$ to $23 \%$. This suggests that NOS neurones are relatively invulnerable to cell death in ad libitum fed animals. Neurones expressing NOS are selectively spared in the aging rat enteric nervous system ${ }^{26}$ as well as in the gall bladder of aging guinea pigs. ${ }^{39}$ In the central nervous system, there is increasing evidence that NO can be either protective or destructive in ischaemic brain injury depending on the cellular source..$^{40}$ In principle, it seems possible that neurones that use NO constitutively may have enhanced defence mechanisms against free radical damage.

The other marker used in the present study was NADH-diaphorase, a marker which has been used in previous studies of age related changes in the rodent enteric nervous system. ${ }^{57}$ A previous study showed that less than half the number of rat myenteric neurones exhibited NADH activity compared with PGP9. $5^{15}$ and that reductions in numbers of $\mathrm{NADH}$ positive neurones in 24 month rats fed a restricted diet were not reflected in similar changes in PGP staining. The inference was that $\mathrm{NADH}$ associated enzymes may be affected by age without a necessary association with cell death. Surprisingly, our counts of $\mathrm{NADH}$ positive neurones, predicted to show a larger decrease than PGP in ad libitum fed 24 month rats, in fact showed a smaller loss $(43 \%$ compared with $52 \%$ ). There was also a $16 \%$ reduction in NADH positive neurone numbers in the RD 24 month group - that is, where we believe there to be no neurone loss. It is therefore possible that reductions in NADH associated enzymes are more marked in relatively invulnerable neurone subpopulations, such as NOS neurones, questioning the suitability of $\mathrm{NADH}$ as a marker for studies of survival in rat myenteric neurones.

Loss of myenteric neurones was not uniformly distributed over the circumference of the gut wall. Those neurones located farthest from the mesentery appear to be less vulnerable to the effects of diet and aging compared with those on the mesenteric aspect of the gut wall. This may relate to recent observations showing that ischaemia induced ulceration generally occurred along the mesenteric areas of the ileum but rarely on the anti-mesenteric aspect. ${ }^{42}$ Thus cell death and ischaemia may be linked in the aging rat myenteric plexus, although how this is related to the effects of ad libitum feeding is not clear.

At present it is not clear if the observed effect of diet on survival of myenteric neurones is related to local effects of diet on the gut or to systemic effects of which loss of enteric neurones forms only a part. Dietary restriction slows the accumulation of the "age pigment" lipofuscin in the brain and heart of aged mice, ${ }^{43}$ perhaps as a result of reduced free radical damage. In addition, preliminary evidence suggests that autonomic innervation to the cerebral vasculature is reduced to a greater extent in 24 month old ad libitum fed SpragueDawley rats compared with similar rats kept on a restricted diet (C) Thrasivoulou and $\mathrm{T}$ Cowen, unpublished). Loss of striatal neurones is delayed but not reversed by dietary restriction. ${ }^{44}$ In the pineal gland, significant declines in melatonin production (which occur in the course of normal aging) can be reversed by dietary restriction. ${ }^{45}$ In the gut, processes essential to normal function such as intracellular protein degradation and mucosal shedding are accelerated by restricting the animal's diet. ${ }^{46}$ These varied observations suggest that diet has systemic as well as local effects on the gut. The possible relationship between these effects remains to be investigated.

Our observations suggest an interaction between longevity and neuronal survival. Dietary restriction increases longevity in rodents. ${ }^{13}{ }^{47}$ Food restriction is just as effective at prolonging life when introduced at six months of age (when juvenile growth is largely complete) as it is at six weeks, ${ }^{14}$ making it unlikely that the effects observed involve a slowing of developmental processes. Restriction of specific components of the diet, such as fat, protein, or minerals does not appear to confer any survival advantage, ${ }^{14}$ suggesting that the effect of dietary restriction on longevity is not due to a specific nutrient but more likely to restriction of energy intake. The high levels of intracellular glucose commonly observed in ad libitum fed animals may cause damage by promoting specific pathways of carbohydrate metabolism that accelerate the aging process. Although aging was thought to induce glucose intolerance and insulin resistance, a recent study $^{48}$ revealed that these changes may be attributed to dietary conditions. These changes are likely to occur at a systemic level, suggesting that the parallel changes that we have shown in neuronal survival and longevity are more than coincidence, and also that it is worth investigating the possibility that dietary regimen makes a major contribution to the maintenance of adequate function in the adult and aging nervous system.

We gratefully acknowledge support from the Anatomical Society of Great Britain and Northern Ireland for funding RJRJ's studentship and the BBSRC (project grant 108/SAG10013 to $\mathrm{TC}$ and others) for supporting VS.

1 Horowitz M, Maddern GJ, Chatterton BE, et al. Changes in gorowitz M, Maddern GJ, Chatterton BE, et al. Changes in
gastric emptying rates with age. Clin Sci 1984;67:213-18. Madsen JL. Effects of gender, age and body mass index on Madsen JL. Effects of gender, age and body mass index on
gastrointestinal transit time. Dig Dis Sci 1992;37:1548-53. 3 Hosoda S, Bamba T, Nakago S, et al. Age-related changes in the gastrointestinal tract. Nutr Rev 1992;50:374-7.

4 Pichel JG, Shen L, Sheng HZ, et al. Defects in enteric innervation and kidney development in mice lacking GDNF. Nature 1996;382:73-6.

5 Gabella G. Fall in the number of myenteric neurons in aging guinea pigs. Gastroenterology 1989;96:1487-93.

6 Karaosmanoglu T, Aygun B, Wade PR et al. Regional differences in the number of neurons in the myenteric plexus of the guinea pig small intestine and colon: an evaluation of colon: an evaluation of 80 .

7 Santer RM, Baker DM. Enteric neuron numbers and sizes in Auerbach's plexus in the small and large intestine of young adult and aged rats. F Auton Nerv Syst 1988;25:5967. 
8 de Souza RR, Moratelli HB, Borges $\mathrm{N}$ et al. Age-induced nerve cell loss in the myenteric plexus of the small intestine in man. Gerontology 1993:39:183-8.

9 Meciano Filho J, Carvalho VC, de Souza RR. Nerve cell loss in the myenteric plexus of the human esophagus in relation to age: a preliminary investigation. Gerontology 1995;41:18 21.

10 Gomes OA, de Souza RR, Liberti EA. A preliminary investigation of the effects of aging on the nerve cell number in the myenteric ganglia of the human colon. Gerontology 1997;43:210-17.

11 Feher E, Penzes L. Density of substance P, vasoactive intestinal polypeptide and somatostatin-containing nerve fibers in the ageing small intestine of the rats. Gerontology 1987;33:341-8.

12 Baker DM, Watson SP, Santer RM. Evidence for a decrease in sympathetic control of intestinal function in the aged rat. Neurobiol Aging 1991;12:363-5.

13 Weindruch R. The retardation of aging by caloric restriction: studies in rodents and primates. Toxicol Pathol $2000 ; 24: 742-5$.

14 Keenan KP, Smith PF, Soper KA. Effect of dietary (caloric) restriction on aging, survival, pathology and toxicology. In: Mohr U, Dungworth DL, Copen CC, eds. Pathobiology of the ageing rat. Washington DC: International Life Sciences, 1994:609-28.

15 Johnson RJR, Schemann M, Santer RM et al. The effects of age on the overall population and on subpopulations of myenteric neurons in the rat intestine. F Anat 1998;192: $479-88$.

16 Gabella G. Neuron size and number in the myenteric plexus of the newborn and adult rat. F Anat 1971;109:81-95.

17 Nowak TV, Harrington B, Kalbfleisch J. Age-related changes in enteric neuromuscular transmission. F Pharm Exp Ther 1990;253:683-7.

18 McDougal JN, Miller MS, Burks TF et al. Age-related changes in the colonic function in rats. Am f Physiol 1984; 247:G542-6.

19 Schemann M, Sann H, Schaaf C et al. Identification of cholinergic neurons in enteric nervous system by antibodies against choline acetyltransferase. Am 7 Physiol 1993; 265:G1005-9.

20 Porter AJ, Wattchow DA, Brookes SJH, et al. Choline acetyltransferase immunoreactivity in the human small and large intestine. Gastroenterology 1996;111:401-8.

21 Merkel IS, Locher J, Burgio K, et al. Physiologic and psychologic characteristics of an elderly population with chronic constipation. Am f Physiol 1993;88:1854-9.

22 Brookes SJ. Neuronal nitric oxide in the gut. $f$ Gastroenterol Hepatol 1993;8:590-603.

23 Aimi Y, Kimura H, Kinoshita T, et al. Histochemical localization of nitric oxide synthase in rat enteric nervous system. Neuroscience 1993;53:553-60.

24 Furness JB, Li ZS, Young HM, et al. Nitric oxide synthase in the enteric nervous system of the guinea-pig: a quantitative the enteric nervous system of the guinea-pig:

25 Cracco C, Filogamo G. Quantitative study of the NADPH diaphorase-positive myenteric neurons of the rat ileum. diaphorase-positive myenteric

26 Santer RM. Survival of the population of NADPHdiaphorase stained myenteric neurons in the small intestine diaphorase stained myenteric neurons in the smal
of aged rats. 7 Auton Nerv Syst 1994;49:115-21.

27 Belai A, Cooper S, Burnstock G. Effect of age on NADPHdiaphorase-containing myenteric neurones of rat ileum and

28 Bockelmann R, Wolf G, Ransmayr G, et al. NADPHdiaphorase/nitric oxide synthase containing neurons in normal and Parkinson's disease putamen. 7 Neural Transm 1994;7:115-21.

29 Eaker EY, Sallustio JE. The distribution of novel intermediate filament proteins defines subpopulations of myenteric neurons in rat intestine. Gastroenterology 1994;107:666-74.

30 Steele PA, Brookes SJ, Costa M. Immunohistochemical identification of cholinergic neurons in the myenteric plexus of guinea-pig small intestine. Neuroscience 1991;45. 227-39.

31 Cowen T, Haven AJ, Burnstock G. Pontamine sky blue: a counterstain for background autofluorescence in fluorescence and immunofluorescence histochemistry. Histochemistry 1985;82:205-8.

32 Gabella G. Detection of nerve cells by a histochemical technic. Experientia 1969;25:218-19.

33 Santer RM, Conboy VB. Prenatal undernutrition permanently decreases enteric neuron number and sympathetic innervation of Auerbach's plexus in the rat. $\mathcal{F}$ Anat 1990;168:57.

34 Warren MA, Bedi K S. Synapse-to-neuron ratios in the visual cortex of adult rats undernourished from birth until 100 days of age. 7 Comp Neurol 1982;210:59-64.

35 Roberts D, Gelperin D, Wiley JW. Evidence for ageassociated reduction in acetyl choline release and smooth muscle response in the rat colon. Am f Physiol 1994;267: 515-22.

36 Lehericy S, Hirsch EC, Cervera P, et al. Selective loss of cholinergic neurons in the ventral striatum of patients with Alzheimer disease. Proc Natl Acad Sci USA 1989;86:85804.

37 Wurtman RJ. Alzheimer's disease. Sci Am 1985;252:48-56.

38 Balaskas C, Saffrey MJ, Burnstock G. Distribution and colocalization of NADPH-diaphorase activity, nitric oxide synthase immunoreactivity, and VIP immunoreactivity in the newly hatched chicken gut. Anat Rec 1995;243:10-18.

39 Siou GP, Belai A, Burnstock G. Age-related changes in galanin- and calretinin-immunoreactive nerves of guineapig gallbladder. Neuroreport 1992;3:990-2.

40 Dalkara T, Moskowitz MA. Neurotoxic and neuroprotective roles of nitric oxide in cerebral ischaemia. Int Rev Neurobiol 1997;40:319-36.

41 Iadecola C. Bright and dark sides of nitric oxide in ischemic brain injury. Trends Neurosci 1997;20:132-9.

42 Anthony A, Pounder RE, Dhillon AP, et al. Vascular anatomy defines the sites of indomethacin induced jejunal ulceration along the mesenteric margin. Gut 1997;47:1-8.

43 Hildegard EE, Kruk P. Dietary restriction reduces fluorescent age pigment accumulation in mice. Exp Gerontol 1981; 16:357-61.

44 Roth GS, Ingram DK, Joseph JA. Delayed loss of striatal neurons during ageing of dietary restricted rats. Brain Res 1993;300:27-32

45 Stokkan KA, Reiter RJ, Nonaka KO, et al. Food restriction retards aging of the pineal gland. Brain Res 1991;545:6672 .

46 Warren MA. Adaptations of the rat small intestine to a single and double period of undernutrition. F Anat 1991;176: 89-97.

47 McCay C, Cromwell M, Maynard L. The effect of retarded growth upon the length of the life span and upon the ultimate size. F Nutr 1935;10:63-79.

48 Barnard RJ, Youngren JF, Martin DA. Diet, not aging, causes skeletal muscle insulin resistance. Gerontology 1995; 41:205-11. 